\title{
Feature tracking cardiac magnetic resonance in systemic light chain amyloidosis
}

\author{
Rebekka Kammerer ${ }^{1}$, Kristin Breuninger ${ }^{1}$, Philipp Matheis ${ }^{1}$, Yannick Sander ${ }^{1}$, Katrin A Scherer ${ }^{1}$, Lukas Rust ${ }^{1}$, \\ Christian Galuschky², Evangelos Giannitsis ${ }^{1}$, Arnt V Kristen ${ }^{1}$, Grigorios Korosoglou', Sebastian Buss ${ }^{1 *}$ \\ From 16th Annual SCMR Scientific Sessions \\ San Francisco, CA, USA. 31 January - 3 February 2013
}

\section{Background}

Systemic light chain amyloidosis (AL) is associated with a high cardiovascular morbidity and mortality. Cardiovascular involvement and determination of prognosis is underestimated by standard imaging parameters. Recently, cardiac deformation analysis of global circumferential and longitudinal strain has been shown to have great clinical impact on the assessment of prognosis and survival in this rare disease. For quantification of cardiac deformation analysis we applied a novel non-invasive post-processing feature tracking algorithm (FTI) on pre-acquired regular CMR SSFP images in healthy volunteers and in patients with AL and sought to investigate wall motion differences between both groups.

\section{Methods}

65 patients (mean age $58 \pm 11$ years; 41 male, 24 female patients) with biopsy proven systemic AL were scanned on a clinical 1.5 T CMR scanner (Philips Achieva). Short axis slices covering entirely both ventricles as well as 2-, 3- and 4-chamber were acquired using standard SSFP-sequences before initiation of specific pharmaceutical AL therapies. The control group consisted of 50 healthy subjects (mean age $58 \pm 5$ years; 23 male, 27 female). Besides the standard CMR parameters for volumes, ejection fraction $(E F)$ and myocardial mass and wall thickness we measured global circumferential and longitudinal strain on SSFP images by the application of the post-processing feature tracking algorithm.

\section{Results}

Global circumferential strain and global longitudinal strain correlated well with left ventricular ejection fraction $\left(\mathrm{r}^{\wedge} 2=0.64, \mathrm{p}<0.05 ; \mathrm{r}^{\wedge} 2=0.47, \mathrm{p}<0.05\right)$. In patients with $\mathrm{AL}$ global longitudinal strain was significantly reduced compared to healthy subjects $(-16.9 \pm 5.1 \%$ vs $-23 \pm 3.3 \%$, $\mathrm{p}<0.05)$, whereas global circumferential strain was not $(-25.1 \pm 7.0 \%$ vs $-27.1 \pm 5.0 \%$, n.s.). In the subgroup analysis of AL patients without cardiac involvement (mean wall thickness $\leq 12 \mathrm{~mm}$ ) global longitudinal strain showed significantly reduced values in comparison to healthy control subjects $(-20.3 \pm 4.7 \%$ vs $-23 \pm 3.3 \%, p<0.05)$, whereas global circumferential strain did not show a significant difference. Patients with an ejection fraction $\geq 50 \%$ already had reduced global longitudinal strains $(-18.5 \pm 4.5 \%$ vs $-23 \pm 3.3 \%, \mathrm{p}<0.05)$, again global circumferential strain did not show a significant difference.

\section{Conclusions}

FTI strain analysis derived from regular SSFP sequences offers the possibility for a retrospective or prospective fast quantitative wall motion assessment of myocardial deformation patterns without specific and time-consuming strain imaging techniques. FTI allows distinguishing between healthy subjects and subjects with AL. Further investigations are necessary to analyze the impact of this new method on clinical outcome in AL patients.

\section{Funding}

none.

Author details

${ }^{1}$ University of Heidelberg, Heidelberg, Germany. ${ }^{2}$ TomTec Imaging Systems, Munich, Germany.

Published: 30 January 2013

${ }^{1}$ University of Heidelberg, Heidelberg, Germany

Full list of author information is available at the end of the article

(c) 2013 Kammerer et al; licensee BioMed Central Ltd. This is an Open Access article distributed under the terms of the Creative Commons Attribution License (http://creativecommons.org/licenses/by/2.0), which permits unrestricted use, distribution, and reproduction in any medium, provided the original work is properly cited. 
doi:10.1186/1532-429X-15-S1-P97

Cite this article as: Kammerer et al.: Feature tracking cardiac magnetic resonance in systemic light chain amyloidosis. Journal of Cardiovascular Magnetic Resonance 2013 15(Suppl 1):P97.

Submit your next manuscript to BioMed Central and take full advantage of:

- Convenient online submission

- Thorough peer review

- No space constraints or color figure charges

- Immediate publication on acceptance

- Inclusion in PubMed, CAS, Scopus and Google Scholar

- Research which is freely available for redistribution

Submit your manuscript at www.biomedcentral.com/submit

() BioMed Central 